OPEN ACCESS

Edited by:

Enzo Lalli,

UMR7275 Institut de pharmacologie moléculaire et cellulaire (IPMC), France

Reviewed by:

Erika Peverelli,

University of Milan, Italy

Mauro Cives,

University of Bari Aldo Moro, Italy

${ }^{*}$ Correspondence: Xianjun Yu yuxianjun@fudanpci.org

Shunrong Ji

jishunrong@fudanpci.org

${ }^{\dagger}$ These authors have contributed equally to this work and share first authorship

Specialty section:

This article was submitted to

Cancer Endocrinology,

a section of the journal

Frontiers in Endocrinology

Received: 10 March 2021 Accepted: 27 April 2021

Published: 19 May 2021

Citation:

Hu Y, Ye Z, Wang F, Qin Y, Xu X, YuX and Ji S (2021) Role of Somatostatin Receptor in Pancreatic Neuroendocrine Tumor Development

Diagnosis, and Therapy.

Front. Endocrinol. 12:679000. doi: 10.3389/fendo.2021.679000

\section{Role of Somatostatin Receptor in Pancreatic Neuroendocrine Tumor Development, Diagnosis, and Therapy}

\author{
Yuheng $\mathrm{Hu}^{1,2,3,4 \dagger}$, Zeng $\mathrm{Ye}^{1,2,3,4 \dagger}$, Fei Wang ${ }^{1,2,3,4}$, Yi Qin ${ }^{1,2,3,4}$, Xiaowu $\mathrm{X} \mathrm{u}^{1,2,3,4}$, \\ Xianjun $\mathrm{Yu}^{1,2,3,4 *}$ and Shunrong $\mathrm{Ji}^{1,2,3,4 *}$
}

${ }^{1}$ Department of Pancreatic Surgery, Fudan University Shanghai Cancer Center, Shanghai, China, ${ }^{2}$ Department of Oncology, Shanghai Medical College, Fudan University, Shanghai, China, ${ }^{3}$ Shanghai Pancreatic Cancer Institute, Shanghai, China,

${ }^{4}$ Pancreatic Cancer Institute, Fudan University, Shanghai, China

Pancreatic neuroendocrine tumors (pNETs) are rare and part of the diverse family of neuroendocrine neoplasms (NENs). Somatostatin receptors (SSTRs), which are widely expressed in NENs, are G-protein coupled receptors that can be activated by somatostatins or its synthetic analogs. Therefore, SSTRs have been widely researched as a diagnostic marker and therapeutic target in pNETs. A large number of studies have demonstrated the clinical significance of SSTRs in PNETs. In this review, relevant literature has been appraised to summarize the most recent empirical evidence addressing the clinical significance of SSTRs in pNETs. Overall, these studies have shown that SSTRs have great value in the diagnosis, treatment, and prognostic prediction of pNETs; however, further research is still necessary.

Keywords: somatostatin receptor, pancreatic neuroendocrine tumor, somatostatin analog, peptide receptor radionuclide therapy, somatostatin receptor imaging

\section{INTRODUCTION}

Pancreatic neuroendocrine tumors (pNETs) originate from the neuroendocrine cells in the pancreas and belong to a group of diverse neuroendocrine neoplasms (NENs) (1). Of all the different types of pancreatic neoplasms, pNETs only account for 1 to $2 \%$ and are therefore defined as uncommon tumors with a clinical incidence of $<1$ patient per 100,000 individuals per year (2). Although considered rare, their clinical incidence has been rising from 0.27 to 1.00 per 100,000 individuals in the last 40 years (3). Furthermore, an increasing number of patients are getting diagnosed in earlier stages, possibly due to improved diagnostic methods, in particular endoscopic and imaging techniques (2). Pancreatic NENs (p-NENs) can be classified into two groups according to the presentation of hormone related symptoms: non-functioning (NF-pNENs) or functioning (FpNENs). A minor fraction (30\%) of pNETs are F-pNENs which may release peptides and hormones, for instance vasoactive intestinal peptide (VIP), gastrin, insulin, glucagon, etc. (4). Even though most of the pNETs arise sporadically, they have been associated with genetical conditions as well, including tuberous sclerosis, von Hippel Lindau disease, multiple endocrine neoplasia (MEN)-1 (which is also accountable for $<5 \%$ of insulinomas and $20-30 \%$ of gastrinomas), 
and neurofibromatosis-1. According to their pathological features, pNETs have been categorized as follows: grade 1, which has a well-differentiated morphology and Ki-67<3\%; grade 2, which also has a well-differentiated morphology and Ki-67 3-20\%; and grade 3, neuroendocrine carcinomas with Ki$67>20 \%$ and poorly differentiated morphology. The World Health Organization (WHO) introduced the following subgroup to a new grading system for pNETs in 2017: welldifferentiated neuroendocrine tumors (NETs) with a Ki-67 $>20 \%$, defined as grade 3 pNET, which is clearly different from poorly differentiated neuroendocrine carcinoma, defined as grade 3 pNEC $(5,6)$. The grade and stage of the pNET determine a patient's prognosis. Tumors of less than $2 \mathrm{~cm}$ usually have a very good prognosis and indicate an indolent grade or biology $(7-10)$. The majority $(>80 \%)$ of patients with localized tumors, stage I or II, that qualify for resection are cured by undergoing solely surgery. The survival of grade 1 and grade 2 pNETs has significantly improved over the last thirty years, reflected by an increase of around 2 to 5 years in median overall survival (OS) (3). A less promising prognosis is seen in advanced grade 3 pNETs, although it is still superior to poorly differentiated (grade 3) pNECs, with a 5-year survival rate of approximately $29 \%$ (11). Surgery is both the main and most significant treatment as well as the only method to cure pNETs. Patients who are unsuitable for surgery can be offered systemic therapy such as peptide receptor radionuclide therapy (PRRT), chemotherapy, targeted therapy, and somatostatin analog (12).

Somatostatin receptors (SSTRs) belong to the superfamily of G protein-coupled receptors (GPCRs) and can be activated by their ligands to exert their physiological function (13). Knowledge of SSTRs and their activation has increased over the last 20 years as a result of many clinical and translational studies and has led to the development of novel treatments (14). The clear effectiveness of somatostatin (SST) analogs (SSAs) has been demonstrated in the treatment of numerous diseases including pancreatitis, nephro- or retinopathy as complications of obesity and diabetes, some types of pain, inflammation, and acromegaly (excessive growth hormone produced by the body) $(15,16)$. In addition, one of the unique features of NETs is the overexpression of SSTRs. Diagnostic and treatment approaches targeting SSTR with SSAs have shown advantages and a promising future prospect $(17-20)$. Figure 1 represents the theranostic significance of SSTRs in patients with NETs.

In this review, we focused on the diagnostic, prognostic, and therapeutic values of SSTRs in the management of pNETs.

\section{BIOLOGY OF SSTRs AND SSAs}

Five subtypes of SSTRs have been discovered (13). Receptor sequences for human SSTRs range in length from 364 amino acids for SSTR5 to 418 amino acids for SSTR3. Unfortunately, crystal structures are not yet available for any SSTR (14). The coding sequences of the genes that encode SSTRs are all intronless, with the exception of SSTR2. The SSTR2 gene could be spliced to generate two distinct receptor proteins, SSTR2A and SSTR2B, which are different in carboxyl termini sequence and length. Only human tissues encompass the unspliced variant

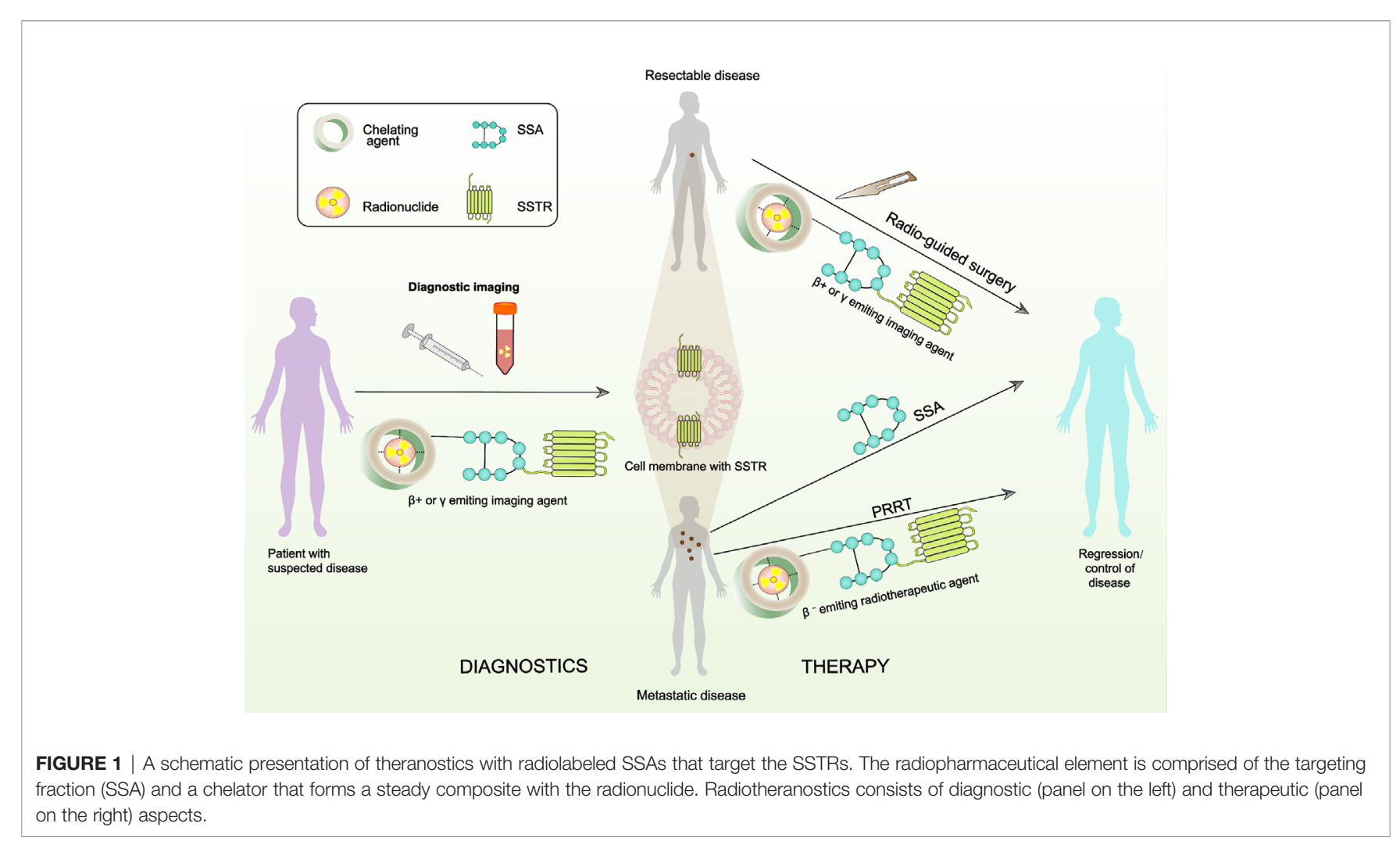


of SSTR2A (21). Although SSAs that target SSTR2 and SSTR5 have important therapeutic functions in the treatment of endocrine tumors, it is remarkable that only a few mutations associated with disease have been detected in the somatotropin release-inhibiting factor (SRIF) system, which consist of seven genes (five receptor genes and two peptide precursors). To date, there has been only one report of an acromegaly patient, who is resistant to octreotide treatment and demonstrated a mutation (R240W) of SSTR5 which evidently affected signaling of the receptor (22). SSTR expression can generally be found in tumors and healthy tissues. SSTRs are based in cellular membranes that consist of seven membrane-spanning domains and are connected to the transmembrane potassium ion channels, calcium ion channels, and intracellular enzymes including adenylate cyclase (ACL) and phosphotyrosine phosphatases (PTPs) like phosphotyrosine phosphatase $\eta$ (PTP $\eta$ ), Src homology phosphatase 1 (SHP1), and Src homology phosphatase 2 (SHP2). After binding to the SST or SSA, intracellular pathways are activated by SSTRs resulting in antiproliferative and antisecretory effects. In addition, activation of SSTR2 and SSTR3 also exert proapoptotic effects as shown in Figure 2 (23-26).

Natural SST, also referred to as SRIF, is a cyclic polypeptide of which two isotypes exist (SST-14 and SST-28, which consist of a $\mathrm{N}$-terminal extension). SST functions as an internal regulator of inhibition and is part of the neuropeptide family. SST-14 as well as SST-28 possess a high affinity to bind each of the five related subtypes of SSTRs (14). The hypothalamus can secrete SST, which leads to the inhibition of essential hormones, for instance thyroid-stimulating hormone and growth hormone. Whereas in the gastrointestinal tract, the production of gastric acid is controlled by SST as well as inhibition of the secretion of diverse hormones, namely cholecystokinin, gastrin, glucagon, VIP, secretin, insulin, and gastric inhibitory polypeptide (GIP). In addition, SST can also reduce motility in the gastrointestinal tract and contraction in the gallbladder through the reduction of blood flow and inhibition of exocrine pancreatic secretion (23).

The induction of various biological effects following activation of the SSTR resulted in identifying them as important therapeutic targets. However, the use of native SST as in vivo therapy is limited because it has a remarkably short half-life. Thus, many different analogs have been developed that could extend the biological actions of SST, prolong its persistence in the body, and often possess increased efficacy. Among these, the very first octapeptide that was developed was octreotide, which could sustain a half-life of 90-120 min following subcutaneous administration. Subsequently, lanreotide and vapreotide were developed, which were cyclooctapeptide SSAs (27). It has been discovered recently that pasireotide (SOM-230) is one of the very first analogs to demonstrate a strong affinity for

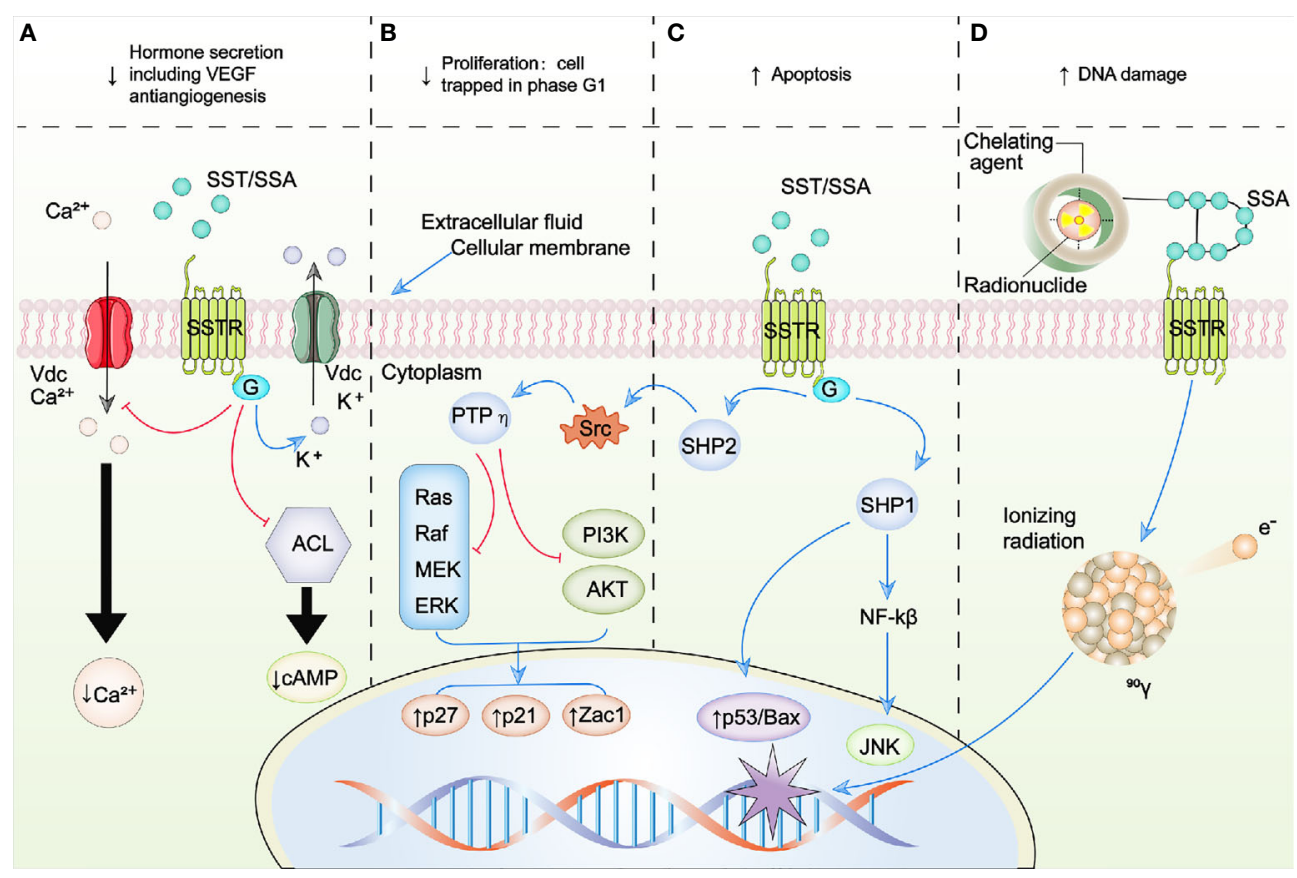

FIGURE 2 Schematic representation of SSTR-targeted therapy. (A-C) represent the intracellular signaling pathways modulated by SSA/SST. (D) represents the schematic of peptide receptor radionuclide therapy (PRRT). Blue arrows, activation; red arrows, inhibition; $\uparrow$, increase; $\downarrow$, decrease; ACL, adenylate cyclase; AKT, protein kinase B; BAX, B-cell lymphoma 2 (BCL2)-associated X protein; Ca2+, calcium; G, G protein; JNK, c-Jun N-terminal kinases; K+, potassium; MEK, mitogenactivated protein kinase kinase; NF $\kappa$ B, nuclear factor kappa B; PI3K, phosphoinositide 3 kinase; PTP $\eta$, phosphotyrosine phosphatase $\eta$; raf, rapidly accelerated fibrosarcoma kinase; ras, RAS kinase; SHP1, Src homology phosphatase 1; SHP2, Src homology phosphatase 2; Src, Rous sarcoma oncogene; SSAs, somatostatin analogues; SST, somatostatin; SSTR, somatostatin receptor; Vdc, voltage-dependent channel; VEGF, vascular endothelial growth factor; Zac1, zinc finger protein regulator of apoptosis and cell cycle arrest. 
the majority of SSTR subtypes, except for SSTR4 (also known as pansomatostatin analog), while octreotide and lanreotide only show a high affinity for SSTR2 and SSTR5 as shown in Table 1 (29). Consequently, the development of synthetic SSAs promoted the clinical use of radiolabeled SSAs, either in imaging, combined with probes in various clinical practices, or as therapy, with a large number of compounds in clinical research. For instance ${ }^{90} \mathrm{Y}$ or ${ }^{177} \mathrm{Lu}-\mathrm{DOTATATE}$ and ${ }^{177} \mathrm{Lu}-$ DOTATOC for PRRT, and SSA labeled with ${ }^{68} \mathrm{Ga}$, such as DOTATOC, DOTATATE, and DOTANOC for somatostatin receptor imaging (SRI) (30). Each of the SSTRs has a high binding affinity to natural SST28 and SST14, while a significant difference is found in the binding affinity of radiolabeled SSAs and synthetic SSAs as shown in Table 1 $(25,28)$.

\section{PROGNOSTIC VALUES OF SSTR EXPRESSION IN PNETS}

Since SSTRs are present on the surface of tumor cells, it provides a molecular basis for long-acting SSAs to be implemented in therapy and diagnostics; thus, the assessment of SSTR expression in pNETs could be important for diagnostic purposes and SSAbased treatment strategies. In previous research, the expression of SSTR subtypes in pNETs was studied mainly through immunohistochemical methods or reverse transcription PCR (RT-PCR) and only a few by receptor autoradiography (3140). Although these studies revealed a heterogeneous SSTR expression pattern, it was confirmed in most studies that SSTR2 is the most commonly expressed subtype in pNET (Table 2).

Furthermore, several studies have assessed the potential value of SSTR expression in the prognosis of pNETs. For instance, Okuwaki et al. (41) retrospectively studied 79 pNET patients to evaluate the correlation between outcomes and the intensity of SSTR2a expression (SSTR-2a score from 0 to 3 by immunohistochemistry criteria). The results revealed that the survival rate of patients with a SSTR-2a score of 0 was $58 \%$ at 1 year, $51 \%$ at 3 years, and $35 \%$ at 5 years; patients with a SSTR-2a score of 1 was $88 \%$ at 1 year, $74 \%$ at 3 years, and $74 \%$ at 5 years; patients with a SSTR-2a score of 2 was $94 \%$ at 1 year, $80 \%$ at 3 years, and $80 \%$ at 5 years; and patients with a SSTR-2a score of 3 was $100 \%$ at 1 year, 3 years, as well as 5 years. As the results clearly indicate, survival was significantly reduced in patients with a SSTR-2a score of 0 compared to those with a higher SSTR2a score, implying that assessing the SSTR2 could be valuable in choosing treatment options and estimating future survival. A retrospective study (42) that followed up 116 patients with gastroenteropancreatic neuroendocrine neoplasms (GEPNENs) showed that the positive expression of SSTR5 and SSTR2 was associated with an improvement in survival. The results indicated that the median OS of patients with a positive expression of SSTR 5 and SSTR2 had not been reached yet prior to publication, while the median OS of patients with a negative expression of SSTR5 and SSTR2 was 7.22 and 3.48 years, respectively; however the pNET subgroup was not analyzed exclusively in this study. Another retrospective study, which included 99 pNET patients, demonstrated by univariate analysis that the expression of SSTR2 was correlated to an improvement in OS, with combined survival rates of $97.5 \%$ at 1 years, $91.5 \%$ at 3 years, and $82.9 \%$ at 5 years. In addition, multivariate analysis demonstrated that positive expression of SSTR2 was a greater prognostic indicator of OS than high Ki-67 (43).

Positive expression of SSTR2 (41-44) and SSTR5 (42) has shown a significant correlation with improved OS, indicating its potential value as prognostic marker and imaging, or therapeutic target. However, an agreement on the significance of the expression of SSTR as a prognostic biomarker in pNETs has not been achieved yet and requires additional evaluation in studies of a prospective nature.

\section{SSTR-TARGETED IMAGING IN pNETs}

As discussed above, most well-differentiated pNETs contain and overexpress SSTRs (see Table 2) that have a higher binding affinity for these SSAs (SSTR2 > SSTR5 and 3, as shown in Table 1).

TABLE 1 | Somatostatin Analog Affinities.

\begin{tabular}{|c|c|c|c|c|c|}
\hline \multirow[t]{2}{*}{ Somatostatin analog } & \multicolumn{5}{|c|}{ Affinity $\left(\mathrm{IC}_{50} \mathrm{nM}\right)$} \\
\hline & SSTR1 & SSTR2 & SSTR3 & SSTR4 & SSTR5 \\
\hline Octreotide & $>1000$ & $0.4-2.1$ & $4.4-34.5$ & $>1,000$ & $5.6-32$ \\
\hline Lanreotide & $>1000$ & $0.5-1.8$ & $43-107$ & $>1,000$ & $0.6-14$ \\
\hline Pasireotide & 9.3 & 1 & 1.5 & $>100$ & 0.16 \\
\hline In-DTPA-octreotide & $>10,000$ & $22 \pm 3.6$ & $182 \pm 13$ & $>1,000$ & $237 \pm 52$ \\
\hline Ga-DOTATOC & $>10,000$ & $2.5 \pm 0.5$ & $613 \pm 140$ & $>1,000$ & $73 \pm 21$ \\
\hline Ga-DOTANOC & $>10,000$ & $1.9 \pm 0.4$ & $40.0 \pm 5.8$ & $260 \pm 74$ & $7.2 \pm 1.6$ \\
\hline Ga-DOTATATE & $>10,000$ & $0.20 \pm 0.04$ & $>1,000$ & $300 \pm 140$ & $377 \pm 18$ \\
\hline Y-DOTATOC & $>10,000$ & $11 \pm 1.7$ & $389 \pm 135$ & $>10,000$ & $114 \pm 29$ \\
\hline Y-DOTATATE & $>10,000$ & $1.6 \pm 0.4$ & $>1,000$ & $523 \pm 239$ & $187 \pm 50$ \\
\hline LU-DOTATATE & $>1,000$ & $2.0 \pm 0.8$ & $162 \pm 16$ & $>1,000$ & $>1,000$ \\
\hline
\end{tabular}

Data from $(25,28)$.

All data are mean $\pm S D$; $I C_{50}$ : half maximum inhibitory concentration $\left(I C_{50}\right.$ depicts the concentration of a drug needed for in vitro inhibition of $50 \%$; the lower the $I C_{50}$, the stronger the affinity). 
TABLE 2 | SSTR expression in p-NETs.

Tumor type

SSTR subtype

\begin{tabular}{|c|c|c|c|c|c|c|c|c|c|c|}
\hline & \multicolumn{2}{|c|}{ SSTR1 } & \multicolumn{2}{|c|}{ SSTR2 } & \multicolumn{2}{|c|}{ SSTR3 } & \multicolumn{2}{|c|}{ SSTR4 } & \multicolumn{2}{|c|}{ SSTR5 } \\
\hline & mRNA & Protein & mRNA & Protein & mRNA & Protein & mRNA & Protein & mRNA & Protein \\
\hline \multirow[t]{3}{*}{$\mathrm{p}-\mathrm{NET}$ in general } & $62 \%(32)$ & $30 \%(69)$ & $90 \%(32)$ & $78 \%(69)$ & $56 \%(32)$ & $78 \%(69)$ & $78 \%(32)$ & $12 \%(25)$ & $81 \%(32)$ & $76 \%(69)$ \\
\hline & $62 \%(21)$ & $36 \%(25)$ & $86 \%(21)$ & $76 \%(25)$ & $86 \%(21)$ & $40 \%(25)$ & & $52 \%(199)$ & $86 \%(21)$ & $56 \%(25)$ \\
\hline & & $53 \%(199)$ & & $55 \%(199)$ & & $29 \%(199)$ & & & & $34 \%(199)$ \\
\hline \multicolumn{11}{|l|}{ Functioning p-NET } \\
\hline Gastrinoma & & $30 \%(33)$ & & $100 \%(33)$ & & 79\%(33) & & & & $76 \%(33)$ \\
\hline \multirow[t]{2}{*}{ Insulinoma } & & $25 \%(16)$ & & $13 \%(16)$ & & $19 \%(16)$ & & $88 \%(16)$ & & $19 \%(16)$ \\
\hline & & $31 \%(36)$ & & $58 \%(36)$ & & $78 \%(36)$ & & & & $78 \%(36)$ \\
\hline
\end{tabular}

The data on mRNA expression is obtained from studies that used RT-PCR (31-34). The data on protein expression is obtained from immunohistochemical studies (35-38, 40) that used SSTR subtype-specific antibodies and receptor autoradiography method with subtype-selective SSTR autoradiography (39). The numbers indicate the percentage of tumors that express the corresponding SSTR subtype amongst the total of tumors investigated; the numbers between parentheses represent the total number of tumors included in these studies.

Therefore, Somatostatin receptor imaging (SRI) combined with radiolabeled SSA $\left({ }^{111} \mathrm{In}\right.$-pentetreotide (Octreoscan) $/{ }^{68} \mathrm{Ga}$ DOTA-SSA PET/CT) is increasingly being used as a diagnostic tool when pNET is suspected (45). A review comparing the sensitivity of different imaging methods for pNETs and their metastases in the liver (see Table 3) showed that SRI has advantages in sensitivity.

As Table 3 evidently shows, ${ }^{111}$ In-pentetreotide has a higher sensitivity overall compared to cross-sectional imaging for the two types of primary pNETs (non-insulinomas) as well as a specific advantage in examining the whole body at once and thereby possibly discovering liver as well as distant metastases (47-51). ${ }^{111}$ In-pentetreotide has an overall sensitivity in pNET of $60-80 \%$ (52). The use of ${ }^{111}$ In-pentetreotide following crosssectional imaging led in 39\% of patients (with a total range of 16$71 \%)$ to an alteration in management $(47,51)$. Among all the distinct pNETs, SRI is generally not conducted in insulinomas since the sensitivity for ${ }^{111}$ In-pentetreotide in benign insulinomas is considered as low, due to the low levels or absence of SSTR2 and SSTR5 in these type of tumors (53).

Different studies have used a variety of ${ }^{68} \mathrm{Ga}$-labeled SSAs (54, 55). These mainly include ${ }^{68} \mathrm{Ga}$-DOTATATE, ${ }^{68} \mathrm{Ga}$-DOTATOC, and ${ }^{68} \mathrm{Ga}$-DOTANOC (54-57). Although these three possess a different affinity for varying subtypes of SSTRs, they do have a high affinity for SSTR2 in common, and reviews including comparative studies have demonstrated that minor or no obvious differences were observed in their performances $(53-55,58,59)$.
Multiple published studies, in which the findings of ${ }^{68} \mathrm{Ga}$-DOTASSA PET/CT were compared to those of ${ }^{111}$ In-pentetreotide SPECT/CT in the exact same group of patients, concluded that ${ }^{68}$ Ga-DOTA-SSA PET/CT had a significantly higher (which varied from 22 to $46 \%$ ) sensitivity in the patients ${ }^{68} \mathrm{Ga}$-DOTA-SSA PET/ CT 95-100\% vs SSTR scintigraphy 45-78\%) (45, 60-63). It has been recommended most recently to replace SRI with ${ }^{111}$ In-pentetreotide SPECT/CT by ${ }^{68}$ Ga-DOTA-SSA PET/CT since it has a higher diagnostic accuracy and sensitivity and requires a smaller dose of radiation $(45,54,55)$. However, a recently published meta-analysis, which only included pNET patients, that evaluated the detection of the primary lesion and its primary staging with ${ }^{68} \mathrm{Ga}$-DOTA-SSA PET/CT demonstrated that the pooled specificity and sensitivity for identifying primary pNET was 95 and 79.6\%, respectively (64). This sensitivity was lower compared to the results of other meta-analysis/ series, which included patients with different type of NETs, and demonstrated a mean sensitivity of 92\% (range between 68 and $100 \%$ ), a relatively high mean specificity of $88 \%$ (range between 50 and 100\%), and a high mean accuracy of $93 \%$ (range between 90 and 97\%) (50, 54, 55, 65-69). These differences might be correlated to the PET/CT's spatial resolution that can cause restriction in the identification of minor pancreatic lesions and the inclusion of higher histopathological grades of pNETs in these studies which could have resulted in an increase of false-negative outcomes due to a lower expression of SSTR (70). Moreover, the inclusion of insulinoma patients could also have contributed to these differences due to their restricted expression of SSTR in

TABLE 3 | The sensitivity of different imaging modalities for pNETs and their metastases in the liver.

\begin{tabular}{|c|c|c|c|c|c|}
\hline \multirow[t]{2}{*}{ Imaging modality } & \multicolumn{5}{|c|}{ Sensitivity (\%) } \\
\hline & Gastrinoma & Insulinoma & pNET $<1.5 \mathrm{~cm}$ & pNET $>2.5 \mathrm{~cm}$ & Liver metastasis \\
\hline CT scan & $5-47$ & $20-63$ & 34 & $50-94$ & $75-100$ \\
\hline $\mathrm{MRI}$ & $10-44$ & $10-85$ & 34 & $60-95$ & $67-100$ \\
\hline US & $0-21$ & $26-50$ & $11-33$ & $30-76$ & $15-77$ \\
\hline Angiography & $15-51$ & $50-60$ & $30-60$ & $60-90$ & $33-86$ \\
\hline EUS & $40-63$ & $71-94$ & 40-90 & $82-100$ & N/A \\
\hline${ }^{111}$ In-pentetreotide & 30-32 & $33-60$ & $29-30$ & $52-96$ & $90-100$ \\
\hline${ }^{68} \mathrm{GaDOTATAC} \mathrm{PET/CT}$ & $68-100$ & $31-90$ & $60-80$ & $68-100$ & $95-100$ \\
\hline
\end{tabular}

Data from (46).

pNET, Pancreatic Neuroendocrine Tumor; CT, Computed Tomography; MRI, Magnetic Resonance Imaging; US, Ultrasound; EUS, Endoscopic Ultrasound. 
comparison with carcinoids, the most common histopathological subtype of GEP-NET, resulting in the potential reduction of SSTRPET sensitivity (71).

${ }^{68}$ Ga-DOTA-SSA PET/CT also has a high sensitivity for identifying metastases in liver, lymph nodes, and distant ones (bone, etc.), which has a great influence on treatment, prognosis, and OS $(50,68,72-75)$. Various studies $(56,76-79)$ have demonstrated that the tumor standardized uptake value (SUV) of ${ }^{68} \mathrm{Ga}$-DOTA-SSA PET/CT is related to progression-free survival (PFS), Ki-67, tumor progression, and tumor grade/differentiation. Another study also found that the SUV of ${ }^{68}$ Ga-DOTA-SSA PET/ CT in NET patients is related to the expression of SSTR2 and can serve as a distinct predictor of OS (44). In addition, it has been demonstrated that the SUV of ${ }^{68}$ Ga-DOTA-SSA PET/CT correlates with the uptake amount of radioligand in PRRT (80), and a maximum cut-off of 16.4 could predict responding lesions with a specificity of $60 \%$ and sensitivity of $95 \%$ (81).

SRI has also demonstrated its value in radioguided surgery (RGS). RGS makes use of radiopharmaceuticals that are uptaken by tumor tissues by preference. Studies found that RGS combined with ${ }^{68} \mathrm{Ga-DOTATATE}$ in GEP-NET patients showed feasibilities in guiding the removal of lymph node metastasis and both intraoperative evaluation as well as establishing the correctness of surgical margins. In addition, it could also be valuable in the identification and removal of minor tumors that were invisible or not palpable in recurrent NET patients, in whom the surgical area is covered with scar tissue $(82,83)$.

These studies suggest that SRI with radiolabeled SSAs have an essential role in identifying the primary tumor, initial staging, restaging, prognosis, intraoperation guidance, and evaluation of the response to treatment in pNET patients. Moreover, SRI can differentiate whether or not patients are suitable for treatment with PRRT. This is a key feature of targeting SSTRs because it provides the opportunity to personalize treatment (also referred to as theranostic approach as shown in Figure 1).

\section{SSTR-TARGETED THERAPY IN PNET}

The therapeutic value of PRRT and SSAs in NETs relies on the biological foundation of SSTR expression on the NET's surface (see Figure 2).

\section{SSA in the Treatment of pNET Antiproliferative Effects}

SSAs function through targeting SSTRs (84). The most studied SSAs are lanreotide autogel and octreotide long-acting release (LAR), which primarily target SSTR5 and SSTR2. Whereas the newest SSA, pasireotide, can target a broader scope of SSTRs, including SSTR1, 2, 3, and 5 as shown in Table $\mathbf{1}(85,86)$. Due to their anti-secretory effects, SSAs were previously only used to regulate symptoms (84). However, at present their antiproliferative effect has been widely confirmed (87).

The PROMID clinical trial was the first to provide solid evidence of the anti-proliferative effect $(88,89)$. This study was a double-blind, placebo-controlled, prospective phase III randomized controlled trial (RCT), in which the effect of octreotide LAR was evaluated in patients who had a metastatic or locally advanced, non-treated grade 1 midgut NET, or an idiopathic NET. The results showed that the increase in median time to progression (TTP) of the tumor was clinically and statistically significant (placebo 6 months $v s$. octreotide LAR 14.3 months and hazard ratio (HR) of 0.34 (95\%-CI $0.20-0.59 ; p=0.000072$ ). The patients in this study who were in the placebo group were permitted to go over to the octreotide LAR group if progression occurred, which is probably the primary cause of TTP differences not resulting in an improvement of the OS. Even though no pNET patients were included in this RCT, the results were still regarded as powerful and led to the addition of octreotide as treatment in pNET patients to the ENETS guidelines $(19,90)$. This was further confirmed by a few small phase II studies and retrospective series that demonstrated the anti-proliferative effect of octreotide LAR in patients with a pNET, of which a majority were low Ki-67 NETs (as longer lasting responses were observed in patients with a low Ki-67 of less than 10) (91). The CLARINET study was a crucial phase III trial, in which the effects of SSA in pNET patients was evaluated (20, 92-94). This randomized, placebo-controlled, and double-blinded study assessed lanreotide autogel in patients who had metastatic or locally advanced, well-differentiated, and non-functioning (except for gastrinomas) GEP-NETs with a low Ki-67 of less than $10 \%$. The (core) study duration was 96 weeks, which was followed by an open label extension (OLE) component. The majority of the included patients were treatment-naïve ( $84 \%$ in both groups) and were in a steady disease state during baseline (95 and 96\% in the placebo and lanreotide group, respectively). The findings demonstrated an advantage in regard to PFS with a HR of 0.58 (95\%-CI $0.32-1.04$ in the core study) (92) and median PFS of 29.7 months in the pNET group (core study and OLE as a whole). The advantage in PFS was seen irrespective to tumor burden (20). Despite the poor response rate (2\%), stabilization of disease was still high (64\%), which resulted in a great disease control rate (DCR) of $66 \%$. Data on the patients, during OLE, that crossed over to the lanreotide autogel group due to disease progression under placebo and were initially already in that group without disease progression at week 96 $(\mathrm{n}=88)$ showed that, interestingly, $50 \%$ of these patients had pNETs (93). The median PFS of pNET patients was 29.7 months, which was shorter compared to the median PFS of all the included patients (38.5 months) (20). A large number of studies have tried to enhance the anti-tumor ability of SSAs by developing novel SSAs like pasireotide LAR (95) or compounds of SSAs combined with other anti-tumor media like everolimus, as demonstrated in the COOPERATE-1 study (96). However, these studies have not yielded any successful results and the clinical use of SSAs in the treatment of pNETs is, at present, still restricted to single agent approaches.

\section{Anti-Secretory Effects}

In patients with malignant insulinoma, SSAs are mainly used as second-line medical therapy to regulate hypoglycemia. A previous study has demonstrated that octreotide can be 
successful in regulating hypoglycemia in a majority of insulinoma patients (97). In addition, pasireotide could be considered as an alternative treatment choice in malignant insulinomas and subsequent recurrence of hypoglycemic incidents since it is capable of regulating hypoglycemia in insulinomas that are resistant to other therapies, such as octreotide LAR, everolimus, and chemotherapy (98). However, SSAs can also exacerbate hypoglycemia through the inhibition of counter-regulatory processes, such as GH and glucagon, in insulinomas that do not express SSTRs (99). High dosages of proton pump inhibitors can effectively decrease oversecretion of gastric acid, although it cannot decrease the abnormal increase of enterochromaffin-like (ECL) cells. On the contrary, multiple studies have shown that the use of SSAs, such as lanreotide and octreotide LAR, in type 1 gastric NETs (related to chronic atrophic gastritis) and type 2 (related to the Zollinger-Ellison syndrome) can suppress the secretion of gastrin and decrease the tumor burden. Their results show that in $50-100 \%$ of gastrinomas, gastric secretion is either decreased or normalized, which resulted in the stabilization of the tumor in $47-75 \%$ of included patients. Furthermore, SSAs may be capable of inhibiting hyperplasia of ECL cells or the growth of type 2 gastric NETs (100-102). Lanreotide and octreotide have demonstrated the ability to quickly reduce diarrhea and migratory necrolytic erythema in glucagonoma patients, despite the sustained rise of glucagon levels in the serum (103-105), whereas pasireotide has been proposed as a suitable treatment approach in first-generation glucagonomas resistant to SSAs. Treatment with octreotide, as an adjuvant, in the rare vipomas was successful in decreasing VIP levels in serum and regulating diarrhea (106-108). Even though it seems contradictory to use SSAs in the treatment of somatostatinomas, a study has shown that octreotide relieved the associated symptoms and successfully decreased the levels of SST in the plasma of three patients (109).

\section{PRRT in the Treatment of pNETs}

The effectiveness of PRRT in NETs is based on the biologic foundation of SSTR expression on the NET's surface. PRRT is comprised of a radionuclide (e.g., $\beta$-emitters Lutetium-177 $\left[{ }^{177} \mathrm{Lu}\right]$ and Yttrium-90 $\left[{ }^{90} \mathrm{Y}\right], \alpha$-emitter Actinum-225 $\left.\left[{ }^{225} \mathrm{Ac}\right]\right)$ which is connected to a chelator (DOTA) that is bound to a SSTR ligand, for instance [Tyr3] octreotide or [Tyr3] octreotate (110). This composite is intravenously given after which the ligand, [Tyr3] octreotate, first connects to the cell surface's SSTR and then supplies emission of $\beta^{-}$radiation with a span of $12 \mathrm{~mm}$ for ${ }^{90} \mathrm{Y}$ and $2 \mathrm{~mm}$ for ${ }^{177} \mathrm{Lu}$ (111). Among the compounds that have been studied, $\beta$-emitters, ${ }^{90} \mathrm{Y}$-DOTATOC and ${ }^{177} \mathrm{Lu}$ DOTATATE, have been the most widely used clinically. However, recently several clinical studies using PRRT with $\alpha$ emitters have demonstrated its strengths compared with $\beta$ emitters, which will be discussed below in more details.

\section{Anti-Tumoral Efficacy}

It is worth noting that no prospective and randomized phase III trials have been conducted with PRRT in pNETs. Although, the
NETTER-1 trial is the biggest study to date that evaluated the effects of PRRT, it unfortunately did not include any pNET patients (18). However, several non-randomized studies have been reviewed and they provided retrospective as well as prospective data on evaluation the use of PRRT with ${ }^{177} \mathrm{Lu}$ DOTATATE in pNET patients $(112,113)$. The results showed a median objective response rate (ORR) of $58 \%$ (with a range between 13 and 73\%), a median DCR of $83 \%$ (with a range between 50 and 94\%), a median OS between 42 and 71 months, and a median PFS ranging between 25 and 34 months. A retrospectively conducted study including 74 GEP NET patients demonstrated that a more elevated ORR (adjusted SWOG criteria) of 73 vs 39\% $(p=0.005)$ was found in pNET patients. This group of patients also seemed to have a longer median OS (57 vs. 45 months); however, this finding was only observed in the univariate analysis $(p=0.037)$ and not in the multivariate analysis $(p=0.173)(112)$. Another retrospective study that included 310 GEP-NET patients showed that the patients with functional pNETs had a decreased disease-specific survival in comparison to patients with non-functional GEPNETs (33 vs. $>48$ months, respectively, $p=0.04$ ) (114). These findings were further underwritten by the outcomes of another retrospective study which had 68 patients included. The results demonstrated a poorer median OS in functional pNETs compared to non-functional pNETs with univariate analysis (45 vs. 63 months, respectively, $p=0.045$ ); however, these findings did not show statistical significance in the multivariate analysis $(p=0.506)(115)$.

To date, the largest study that evaluated ${ }^{90}$ Y-DOTATOC has been a prospective phase II trial in which 342 pNET patients were enrolled (divided in functional pNET, $\mathrm{n}=47$ and nonfunctional pNET, $\mathrm{n}=295$ ). Nearly $50 \%$ of the pNET patients (ORR $=47 \%$, according to the RECIST criteria) had tumor response. In addition, the study revealed a mean OS of 60 months in the group of nonfunctional pNET patients (116).

Although PRRT with $\beta$-emitters has shown a good clinical effect, recently, a more promising radionuclide, $\alpha$-emitters has attracted increased attention in radionuclide therapy $(117,118)$. Radioisotopes that emit $\alpha$-particles which have higher energy and shorter penetration range in comparison with $\beta$-particles, induce a higher probability of double strand breaks and minimum damage to surrounding healthy tissue $(119,120)$. These $\alpha$-emitters have demonstrated promising therapeutic effects in a few pre-clinical in vitro (121-123) or in vivo (124, 125) studies. Currently, the only clinical experience with ${ }^{213} \mathrm{Bi}$ DOTATOC included seven patients with advanced NETs with liver metastases who were refractory to treatment with ${ }^{90} \mathrm{Y}$ DOTATOC or ${ }^{177}$ Lu-DOTATOC (117). It demonstrated lower toxicity, better specific tumor binding than with $\beta$-irradiation, and partial remission of metastases. Two years after receiving ${ }^{213}$ Bi-DOTATOC targeted alpha therapy (TAT), all seven patients were still alive. A study with another type of $\alpha$ emitters, ${ }^{225} \mathrm{Ac}$, had included 10 patients with progressive NETs after $\beta$-PRRT. In line with ${ }^{213} \mathrm{Bi},{ }^{225} \mathrm{Ac}$-DOTATOC was well tolerated and effective (126). Another recent study with ${ }^{225}$ Ac-DOTATATE confirmed the potential of these radiotracers 
as an additional, and valuable, treatment option for patients who are refractory to ${ }^{177} \mathrm{Lu}$-DOTATATE therapy. The included 32 patients, who previously received ${ }^{177} \mathrm{Lu}$-DOTATATE therapy, were treated with ${ }^{225}$ Ac-DOTATATE. Of them, 24 patients were assessed as responsive, with nine as stabilized disease and 15 partial remissions (127). The clinical experience with TAT in NETs has shown very promising results even in patients refractory to treatment with $\beta$-particles. However, further investigations are needed due to the limited amount of clinical evidence.

\section{Efficacy in Hormone-Related Symptoms}

There have been two studies that studied PRRT as treatment of gastrinomas $(128,129)$. In one of these studies 11 gastrinoma patients were assessed, and the results indicated that every patient experienced improvement of their symptoms although, the median OS was just 14 months (129). In contrast, the findings of the other study,which assessed 36 gastrinoma patients, revealed an ORR of $30 \%$ as well as a clinically observed response rate of $16 \%$ (128). In addition, the median OS was reported to be 45 months in the patients that were considered as responders. In terms of malignant insulinomas, there is a limited amount of data by means of case reports or series that indicate a positive result of PRRT in stabilization of disease as well as hypoglycemia $(130,131)$. Another recently published retrospective study, which had 34 functional pNET patients with metastasis and persistent hormonal symptoms included in it, reported that most patients (71\%) showed a significant improvement in terms of the functional syndrome and $80 \%$ of them showed a decrease in the circulating levels of related hormones. Following PRRT, the outcomes demonstrated a median PFS of 18.1 months, which was correlated to a coexisting improvement of quality of life (132).

Overall, PRRT can be considered as a real innovation in the treatment of NETs. Even though randomized and prospective data of PRRT in pNETs is limited, the data that is available today indicates that it is an effective treatment for pNETs and should be studied further.

\section{FUTURE PROSPECTIVE}

\section{SSTR Antagonists in Imaging and Therapy}

SRI and PRRT use radiolabeled SSAs (see Table 1), which are only SSTR agonists as mentioned previously, mainly because it is believed in general that agonists would be the most suitable for imaging since they are internalized, while SSTR antagonists are not (133). It has been uncovered recently that SSTR antagonists with radiolabeling produce more superior imaging than SSTR agonists with radiolabeling $(133,134)$. A study conducted in vitro with SSTR3 antagonists revealed that it detected 76-fold more sites of binding in comparison to the SSTR3 agonist (134). Thereafter, a few studies which only included a minor amount of NET patients (pNETs as well as GI-NETs were included) showed that SSTR2 antagonists with radiolabeling, i.e., ${ }^{111} \mathrm{In}-$

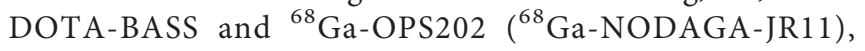

demonstrated more superior imaging of the tumor and higher sensitivity than SSTR2 agonists with radiolabeling (28, 133-136). These results have led to the option of using ${ }^{177} \mathrm{Lu}$-radiolabeled SSTR2 antagonists in PRRT instead of ${ }^{177}$ Lu-radiolabeled SSTR2 agonists. The results of another preclinical study (137) conducted in vivo with SSTR2 positive cells and in mice with tumors, showed that the tumor uptake was five times more with SSTR2 radiolabeled antagonists, ${ }^{177}$ Lu-DOTA-JR11, compared to the SSTR2 radiolabeled agonist, ${ }^{177} \mathrm{Lu}$-DOTA-octreotate, which led to a longer delay in growth. When research using these two SSTR2 radiolabeled compounds were expanded to four advanced NET patients (134), the ${ }^{177}$ Lu-DOTA-JR11 provided 1.7-10.6-fold higher tumor uptake dose compared to the agonist, ${ }^{177} \mathrm{Lu}$-DOTA-octreotate, which resulted in a partial remission in half of the enrolled patients. These findings indicate that SSTR2 radiolabeled antagonists have the potential of being an improved agent in comparison to SSTR2 radiolabeled agonists in pNET/ NET imaging and PRRT.

\section{CONCLUSION}

Although pNET is a highly heterogeneous disease, SSTR is expressed in most pNETs, which provides the opportunity for promising approaches and strategies in diagnosing, treating, and predicting the prognosis of pNET patients. In the previous few decades magnificent progress has been made in the clinical significance of SSTRs in pNETs. SRI and therapies with radiolabeled SSA have shown significant value in clinical practice and has been recommended in various guidelines. However, an even more promising agent, namely radiolabeled somatostatin antagonists, has shown its superiority compared with agonists. Despite the accumulation of evidence that SSTRtargeted or related therapies (e.g., SSAs and SSTR-targeted PRRT) are safe and effective options for refractory or unresectable pNETs, most SSTR-targeted therapies target SSTR2, and for those SSTR2-negative patients, more effective therapeutic approaches targeting other SSTRs are urgently needed. More and larger randomized prospective trials, conducted in multiple centers with a long-term follow-up are desperately needed as well. In addition, research deciphering crystal structures for the five SSTRs are also needed, in particular to uncover the exact signaling pathways of SSTR ligands and SSAs that underlie its antitumor effects and to facilitate the development of novel SSTR subtype-selective agents, along with the detection and selection of appropriate candidate patients who could benefit from these therapies.

\section{AUTHOR CONTRIBUTIONS}

SJ conceived of the presented idea. $\mathrm{YH}$ and $\mathrm{ZY}$ wrote the manuscript. FW and YQ searched the literature. XX and XY supervised the project. All authors contributed to the article and approved the submitted version. 


\section{FUNDING}

This work was supported by grants from National Science Foundation of China (No.81871950 and 81972250); Scientific
Innovation Project of Shanghai Education Committee (2019-01-0700-07-E00057); and National Science Foundation for Distinguished Young Scholars of China [81625016], Shanghai Municipal Commission of Health and Family Planning (No. 2018YQ06).

\section{REFERENCES}

1. Alsidawi S, Westin GFM, Hobday TJ, Halfdanarson TR. Pancreatic Neuroendocrine Tumors: A Population-Based Analysis of Epidemiology and Outcomes. J Clin Oncol (2017) 35(4_suppl):401-. doi: 10.1200/ JCO.2017.35.4_suppl.401

2. Hallet J, Law CHL, Cukier M, Saskin R, Liu N, Singh S. Exploring the Rising Incidence of Neuroendocrine Tumors: A Population-Based Analysis of Epidemiology, Metastatic Presentation, and Outcomes. Cancer (2015) 121 (4):589-97. doi: 10.1002/cncr.29099

3. Dasari A, Shen C, Halperin D, Zhao B, Zhou SH, Xu Y, et al. Trends in the Incidence, Prevalence, and Survival Outcomes in Patients With Neuroendocrine Tumors in the United States. JAMA Oncol (2017) 3 (10):1335-42. doi: 10.1001/jamaoncol.2017.0589

4. Ito T, Lee L, Jensen RT. Treatment of Symptomatic Neuroendocrine Tumor Syndromes: Recent Advances and Controversies. Expert Opin Pharmacother (2016) 17(16):2191-205. doi: 10.1080/14656566.2016.1236916

5. Kim JY, Hong S-M, Ro JY. Recent Updates on Grading and Classification of Neuroendocrine Tumors. Ann Diagn Pathol (2017) 29:11-6. doi: 10.1016/ j.anndiagpath.2017.04.005

6. Choe J, Kim KW, Kim HJ, Kim DW, Kim KP, Hong S-M, et al. What Is New in the 2017 World Health Organization Classification and 8th American Joint Committee on Cancer Staging System for Pancreatic Neuroendocrine Neoplasms? Korean J Radiol (2019) 20(1):5-17. doi: 10.3348/kjr.2018.0040

7. Marchegiani G, Landoni L, Andrianello S, Masini G, Cingarlini S, D’Onofrio $M$, et al. Patterns of Recurrence After Resection for Pancreatic Neuroendocrine Tumors: Who, When, and Where? Neuroendocrinology (2019) 108(3):161-71. doi: 10.1159/000495774

8. Teo RYA, Teo TZ, Tai DWM, Tan DM, Ong S, Goh BKP. Systematic Review of Current Prognostication Systems for Pancreatic Neuroendocrine Neoplasms. Surgery (2019) 165(4):672-85. doi: 10.1016/j.surg.2018.10.031

9. Landoni L, Marchegiani G, Pollini T, Cingarlini S, D’Onofrio M, Capelli P, et al. The Evolution of Surgical Strategies for Pancreatic Neuroendocrine Tumors (Pan-Nens) Time-trend and Outcome Analysis From 587 Consecutive Resections at a High-volume Institution. Ann Surg (2019) 269(4):725-32. doi: 10.1016/j.pan.2018.05.377

10. Sallinen VJ, Le Large TTY, Tieftrunk E, Galeev S, Kovalenko Z, Haugvik SP, et al. Prognosis of Sporadic Resected Small $(<=2 \mathrm{Cm})$ Nonfunctional Pancreatic Neuroendocrine Tumors - a Multi-Institutional Study. HPB (Oxford) (2018) 20(3):251-9. doi: 10.1016/j.hpb.2017.08.034

11. Basturk O, Yang ZH, Tang LH, Hruban RH, Adsay V, McCall CM, et al. The High-grade (Who G3) Pancreatic Neuroendocrine Tumor Category is Morphologically and Biologically Heterogenous and Includes Both Well Differentiated and Poorly Differentiated Neoplasms. Am J Surg Pathol (2015) 39(5):683-90. doi: 10.1097/PAS.0000000000000408

12. Pavel M, Öberg K, Falconi M, Krenning E, Sundin A, Perren A, et al. Gastroenteropancreatic Neuroendocrine Neoplasms: ESMO Clinical Practice Guidelines for Diagnosis, Treatment and Follow-Up. Ann Oncol: Off J Eur Soc Med Oncol (2020) 31(7):844-60. doi: 10.1016/j.annonc.2020.03.304

13. Patel Y, Srikant C. Somatostatin Receptors. Trends Endocrinol Metabol: TEM (1997) 8(10):398-405. doi: 10.1016/S1043-2760(97)00168-9

14. Günther T, Tulipano G, Dournaud P, Bousquet C, Csaba Z, Kreienkamp HJ, et al. International Union of Basic and Clinical Pharmacology. CV. Somatostatin Receptors: Structure, Function, Ligands, and New Nomenclature. Pharmacol Rev (2018) 70(4):763-835. doi: 10.1124/ pr.117.015388

15. Weckbecker G, Lewis I, Albert R, Schmid H, Hoyer D, Bruns C. Opportunities in Somatostatin Research: Biological, Chemical and Therapeutic Aspects. Nat Rev Drug Discovery (2003) 2(12):999-1017. doi: $10.1038 /$ nrd 1255

16. Rai U, Thrimawithana TR, Valery C, Young SA. Therapeutic Uses of Somatostatin and its Analogues: Current View and Potential Applications. Pharmacol Ther (2015) 152:98-110. doi: 10.1016/j.pharmthera.2015.05.007

17. Baumann T, Rottenburger C, Nicolas G, Wild D. Gastroenteropancreatic Neuroendocrine Tumours (GEP-NET) - Imaging and Staging. Best Pract Res Clin Endocrinol Metab (2016) 30(1):45-57. doi: 10.1016/j.beem.2016.01.003

18. Strosberg J, El-Haddad G, Wolin E, Hendifar A, Yao J, Chasen B, et al. Phase 3 Trial of Lu-Dotatate for Midgut Neuroendocrine Tumors. New Engl J Med (2017) 376(2):125-35. doi: 10.1056/NEJMoa1607427

19. Pavel M, O’Toole D, Costa F, Capdevila J, Gross D, Kianmanesh R, et al. Enets Consensus Guidelines Update for the Management of Distant Metastatic Disease of Intestinal, Pancreatic, Bronchial Neuroendocrine Neoplasms (NEN) and NEN of Unknown Primary Site. Neuroendocrinology (2016) 103(2):172-85. doi: 10.1159/000443167

20. Wolin EM, Pavel M, Cwikla JB, Phan AT, Raderer M, Sedlackova E, et al. Final Progression-Free Survival (PFS) Analyses for Lanreotide Autogel/ Depot $120 \mathrm{Mg}$ in Metastatic Enteropancreatic Neuroendocrine Tumors (Nets): The CLARINET Extension Study. J Clin Oncol (2017) 35:4089. doi: 10.1200/JCO.2017.35.15_suppl.4089

21. Vanetti M, Kouba M, Wang X, Vogt G, Höllt V. Cloning and Expression of a Novel Mouse Somatostatin Receptor (SSTR2B). FEBS Lett (1992) 311 (3):290-4. doi: 10.1016/0014-5793(92)81122-3

22. Ballare E, Persani L, Lania AG, Filopanti M, Giammona E, Corbetta S, et al. Mutation of Somatostatin Receptor Type 5 in an Acromegalic Patient Resistant to Somatostatin Analog Treatment. J Clin Endocrinol Metab (2001) 86(8):3809-14. doi: 10.1210/jcem.86.8.7787

23. Lamberts SW, van der Lely AJ, de Herder WW, Hofland LJ. Octreotide. New Engl J Med (1996) 334(4):246-54. doi: 10.1056/NEJM199601253340408

24. Dasgupta P. Somatostatin Analogues: Multiple Roles in Cellular Proliferation, Neoplasia, and Angiogenesis. Pharmacol Ther (2004) 102 (1):61-85. doi: 10.1016/j.pharmthera.2004.02.002

25. Barbieri F, Bajetto A, Pattarozzi A, Gatti M, Würth R, Thellung S, et al. Peptide Receptor Targeting in Cancer: The Somatostatin Paradigm. Int J Pept (2013) 2013:926295. doi: 10.1155/2013/926295

26. Abdel-Rahman O, Lamarca A, Valle JW, Hubner RA. Somatostatin Receptor Expression in Hepatocellular Carcinoma: Prognostic and Therapeutic Considerations. Endocr Relat Cancer (2014) 21(6):R485-93. doi: 10.1530/ ERC-14-0389

27. Patel Y. Somatostatin and its Receptor Family. Front Neuroendocrinol (1999) 20(3):157-98. doi: 10.1006/frne.1999.0183

28. Fani M, Nicolas GP, Wild D. Somatostatin Receptor Antagonists for Imaging and Therapy. J Nucl Med (2017) 58(Suppl 2):61s-6s. doi: 10.2967/jnumed.116.186783

29. Schmid HA. Pasireotide (SOM230): Development, Mechanism of Action and Potential Applications. Mol Cell Endocrinol (2008) 286(1-2):69-74. doi: 10.1016/j.mce.2007.09.006

30. Ambrosini V, Fani M, Fanti S, Forrer F, Maecke H. Radiopeptide Imaging and Therapy in Europe. J Nucl Med: Off Publ Soc Nucl Med (2011) 52 (Supplement 2):42S-55S. doi: 10.2967/jnumed.110.085753

31. Nakayama Y, Wada R, Yajima N, Hakamada K, Yagihashi S. Profiling of Somatostatin Receptor Subtype Expression by Quantitative PCR and Correlation With Clinicopathological Features in Pancreatic Endocrine Tumors. Pancreas (2010) 39(8):1147-54. doi: 10.1097/MPA. 0b013e3181e78120

32. O'Toole D, Saveanu A, Couvelard A, Gunz G, Enjalbert A, Jaquet P, et al. The Analysis of Quantitative Expression of Somatostatin and Dopamine Receptors in Gastro-Entero-Pancreatic Tumours Opens New Therapeutic Strategies. Eur J Endocrinol (2006) 155(6):849-57. doi: 10.1530/eje.1.02307

33. Jaïs P, Terris B, Ruszniewski P, LeRomancer M, Reyl-Desmars F, Vissuzaine C, et al. Somatostatin Receptor Subtype Gene Expression in Human 
Endocrine Gastroentero-Pancreatic Tumours. Eur J Clin Invest (1997) 27 (8):639-44. doi: 10.1046/j.1365-2362.1997.1740719.x

34. Papotti M, Bongiovanni M, Volante M, Allì E, Landolfi S, Helboe L, et al. Expression of Somatostatin Receptor Types 1-5 in 81 Cases of Gastrointestinal and Pancreatic Endocrine Tumors. A Correlative Immunohistochemical and Reverse-Transcriptase Polymerase Chain Reaction Analysis. Virchows Archiv: An Int J Pathol (2002) 440(5):461-75. doi: 10.1007/s00428-002-0609-x

35. Kulaksiz H, Eissele R, Rössler D, Schulz S, Höllt V, Cetin Y, et al. Identification of Somatostatin Receptor Subtypes 1, 2A, 3, and 5 in Neuroendocrine Tumours With Subtype Specific Antibodies. Gut (2002) 50(1):52-60. doi: 10.1136/gut.50.1.52

36. Zamora V, Cabanne A, Salanova R, Bestani C, Domenichini E, Marmissolle F, et al. Immunohistochemical Expression of Somatostatin Receptors in Digestive Endocrine Tumours. Digestive Liver Dis: Off I Ital Soc Gastroenterol Ital Assoc Study Liver (2010) 42(3):220-5. doi: 10.1016/j.dld.2009.07.018

37. Fjällskog M, Ludvigsen E, Stridsberg M, Oberg K, Eriksson B, Janson E. Expression of Somatostatin Receptor Subtypes 1 to 5 in Tumor Tissue and Intratumoral Vessels in Malignant Endocrine Pancreatic Tumors. Med Oncol (Northwood London England) (2003) 20(1):59-67. doi: 10.1385/ MO:20:1:59

38. Song KB, Kim SC, Kim JH, Seo DW, Hong SM, Park KM, et al. Prognostic Value of Somatostatin Receptor Subtypes in Pancreatic Neuroendocrine Tumors. Pancreas (2016) 45(2):187-92. doi: 10.1097/MPA.0000000000000493

39. Reubi J, Waser B. Concomitant Expression of Several Peptide Receptors in Neuroendocrine Tumours: Molecular Basis for In Vivo Multireceptor Tumour Targeting. Eur J Nucl Med Mol Imag (2003) 30(5):781-93. doi: 10.1007/s00259-003-1184-3

40. Portela-Gomes G, Stridsberg M, Grimelius L, Rorstad O, Janson E. Differential Expression of the Five Somatostatin Receptor Subtypes in Human Benign and Malignant Insulinomas - Predominance of Receptor Subtype 4. Endocr Pathol (2007) 18(2):79-85. doi: 10.1007/s12022-007-0014-8

41. Okuwaki K, Kida M, Mikami T, Yamauchi H, Imaizumi H, Miyazawa S, et al. Clinicopathologic Characteristics of Pancreatic Neuroendocrine Tumors and Relation of Somatostatin Receptor Type 2A to Outcomes. Cancer (2013) 119(23):4094-102. doi: 10.1002/cncr.28341

42. Wang Y, Wang W, Jin K, Fang C, Lin Y, Xue L, et al. Somatostatin Receptor Expression Indicates Improved Prognosis in Gastroenteropancreatic Neuroendocrine Neoplasm, and Octreotide Long-Acting Release is Effective and Safe in Chinese Patients With Advanced Gastroenteropancreatic Neuroendocrine Tumors. Oncol Lett (2017) 13(3):1165-74. doi: 10.3892/ ol.2017.5591

43. Shreya M, dRP R, Preetjote G, Juliana A, Lisa DU, Anubhav M, et al. Somatostatin Receptor SSTR-2a Expression is a Stronger Predictor for Survival Than Ki-67 in Pancreatic Neuroendocrine Tumors. Medicine (2015) 94(40):e1281. doi: 10.1097/MD.0000000000001281

44. Brunner P, Jörg A-C, Glatz K, Bubendorf L, Radojewski P, Umlauft M, et al. The Prognostic and Predictive Value of Sstr-Immunohistochemistry and Sstr-Targeted Imaging in Neuroendocrine Tumors. Eur J Nucl Med Mol Imag (2017) 44(3):468-75. doi: 10.1007/s00259-016-3486-2

45. Graham MM, Gu X, Ginader T, Breheny P, Sunderland JJ. Ga-68-DOTATOC Imaging of Neuroendocrine Tumors: A Systematic Review and Metaanalysis. J Nucl Med (2017) 58(9):1452-8. doi: 10.2967/jnumed.117.191197

46. Lee L, Ito T, Jensen RT. Imaging of Pancreatic Neuroendocrine Tumors: Recent Advances, Current Status, and Controversies. Expert Rev Anticancer Ther (2018) 18(9):837-60. doi: 10.1080/14737140.2018.1496822

47. Barrio M, Czernin J, Fanti S, Ambrosini V, Binse I, Du L, et al. The Impact of Somatostatin Receptor-Directed PET/CT on the Management of Patients With Neuroendocrine Tumor: A Systematic Review and Meta-Analysis. J Nucl Med (2017) 58(5):756-61. doi: 10.2967/jnumed.116.185587

48. van Essen M, Sundin A, Krenning EP, Kwekkeboom DJ. Neuroendocrine Tumours: The Role of Imaging for Diagnosis and Therapy. Nat. Rev. Endocrinol. (2014) 10(2):102-14. doi: 10.1038/nrendo.2013.246

49. Gibril F, Reynolds JC, Doppman JL, Chen CC, Venzon DJ, Termanini B, et al. Somatostatin Receptor Scintigraphy: Its Sensitivity Compared With That of Other Imaging Methods in Detecting Primary and Metastatic Gastrinomas - a Prospective Study. Ann Intern Med (1996) 125(1):26-+. doi: 10.7326/0003-4819-125-1-199607010-00005
50. Gibril F, Doppman JL, Reynolds JC, Chen CC, Sutliff VE, Yu F, et al. Bone Metastases in Patients With Gastrinomas: A Prospective Study of Bone Scanning, Somatostatin Receptor Scanning, and Magnetic Resonance Image in Their Defection, Frequency, Location, and Effect of Their Detection on Management. J Clin Oncol (1998) 16(3):1040-53. doi: 10.1200/JCO.1998.16.3.1040

51. Gibril F, Jensen R. Diagnostic Uses of Radiolabelled Somatostatin Receptor Analogues in Gastroenteropancreatic Endocrine Tumours. Digestive Liver Dis: Off J Ital Soc Gastroenterol Ital Assoc Study Liver (2004) 36(Supplement 1):S106-20. doi: 10.1016/j.dld.2003.11.024

52. Sundin A, Arnold R, Baudin E, Cwikla JB, Eriksson B, Fanti S, et al. Enets Consensus Guidelines for the Standards of Care in Neuroendocrine Tumors: Radiological, Nuclear Medicine and Hybrid Imaging. Neuroendocrinology (2017) 105(3):212-44. doi: 10.1159/000471879

53. Dromain C, Deandreis D, Scoazec JY, Goere D, Ducreux M, Baudin E, et al. Imaging of Neuroendocrine Tumors of the Pancreas. Diagn Interv Imaging (2016) 97(12):1241-57. doi: 10.1016/j.diii.2016.07.012

54. Ito T, Jensen RT. Molecular Imaging in Neuroendocrine Tumors: Recent Advances, Controversies, Unresolved Issues, and Roles in Management. Curr Opin Endocrinol Diabetes Obes (2017) 24(1):15-24. doi: 10.1097/ MED.0000000000000300

55. Ambrosini V, Morigi JJ, Nanni C, Castellucci P, Fanti S. Current Status of PET Imaging of Neuroendocrine Tumours (18F FDOPA, 68Ga Tracers, 11C/18F -HTP). Q J Nucl Med Mol Imaging (2015) 59(1):58-69.

56. Wild D, Bomanji JB, Benkert P, Maecke H, Ell PJ, Reubi JC, et al. Comparison of Ga-68-DOTANOC and Ga-68-DOTATATE Pet/Ct Within Patients With Gastroenteropancreatic Neuroendocrine Tumors. J Nucl Med (2013) 54(3):364-72. doi: 10.2967/jnumed.112.111724

57. Johnbeck CB, Knigge U, Kjaer A. PET Tracers for Somatostatin Receptor Imaging of Neuroendocrine Tumors: Current Status and Review of the Literature. Future Oncol (2014) 10(14):2259-77. doi: 10.2217/fon.14.139

58. Velikyan I, Sundin A, Sorensen J, Lubberink M, Sandstrom M, Garske-Roman U, et al. Quantitative and Qualitative Intrapatient Comparison of Ga-68-DOTATOC and Ga-68-DOTATATE: Net Uptake Rate for Accurate Quantification. J Nucl Med (2014) 55(2):204-10. doi: 10.2967/jnumed.113.126177

59. Yang J, Kan Y, Ge BH, Yuan L, Li C, Zhao W. Diagnostic Role of Gallium-68 DOTATOC and Gallium-68 Dotatate PET in Patients With Neuroendocrine Tumors: A Meta-Analysis. Acta Radiol (2014) 55(4):389-98. doi: 10.1177/ 0284185113496679

60. Van Binnebeek S, Vanbilloen B, Baete K, Terwinghe C, Koole M, Mottaghy FM, et al. Comparison of Diagnostic Accuracy of In-111-pentetreotide SPECT and Ga-68-DOTATOC Pet/Ct: A Lesion-by-Lesion Analysis in Patients With Metastatic Neuroendocrine Tumours. Eur Radiol (2016) 26 (3):900-9. doi: 10.1007/s00330-015-3882-1

61. Deppen SA, Liu E, Blume JD, Clanton J, Shi C, Jones-Jackson LB, et al. Safety and Efficacy of Ga-68-DOTATATE PET/CT for Diagnosis, Staging, and Treatment Management of Neuroendocrine Tumors. J Nucl Med (2016) 57 (5):708-14. doi: 10.2967/jnumed.115.163865

62. Sadowski SM, Neychev V, Millo C, Shih J, Nilubol N, Herscovitch P, et al. Prospective Study of Ga-68-DOTATATE Positron Emission Tomography/ Computed Tomography for Detecting Gastro-Entero-Pancreatic Neuroendocrine Tumors and Unknown Primary Sites. J Clin Oncol (2016) 34(6):588-+. doi: 10.1200/JCO.2015.64.0987

63. Lee I, Paeng JC, Lee SJ, Shin CS, Jang J-Y, Cheon GJ, et al. Comparison of Diagnostic Sensitivity and Quantitative Indices Between Ga-68-Dotatoc PET/CT and In-111-Pentetreotide SPECT/CT in Neuroendocrine Tumors: A Preliminary Report. Nucl Med Mol Imaging (2015) 49(4):284-90. doi: 10.1007/s13139-015-0356-y

64. Bauckneht M, Albano D, Annunziata S, Santo G, Guglielmo P, Frantellizzi $\mathrm{V}$, et al. Somatostatin Receptor Pet/Ct Imaging for the Detection and Staging of Pancreatic Net: A Systematic Review and Meta-Analysis. Diagn (Basel Switzerland) (2020) 10(8):598. doi: 10.3390/diagnostics10080598

65. Deppen SA, Blume J, Bobbey AJ, Shah C, Graham MM, Lee P, et al. Ga-68DOTATATE Compared With In-111-DTPA-Octreotide and Conventional Imaging for Pulmonary and Gastroenteropancreatic Neuroendocrine Tumors: A Systematic Review and Meta-Analysis. J Nucl Med (2016) 57 (6):872-8. doi: 10.2967/jnumed.115.165803

66. Skoura E, Michopoulou S, Mohmaduvesh M, Panagioddis E, Al Harbi M, Toumpanakis C, et al. The Impact of Ga-68-DOTATATE Pet/Ct Imaging on 
Management of Patients With Neuroendocrine Tumors: Experience From a National Referral Center in the United Kingdom. J Nucl Med (2016) 57 (1):34-40. doi: 10.2967/jnumed.115.166017

67. Mojtahedi A, Thamake S, Tworowska I, Ranganathan D, Delpassand ES. The Value of Ga-68-DOTATATE PET/CT in Diagnosis and Management of Neuroendocrine Tumors Compared to Current FDA Approved Imaging Modalities: A Review of Literature. Am J Nucl Med Mol Imaging (2014) 4 (5):426-34.

68. Merola E, Pavel ME, Panzuto F, Capurso G, Cicchese N, Rinke A, et al. Functional Imaging in the Follow-Up of Enteropancreatic Neuroendocrine Tumors: Clinical Usefulness and Indications. J Clin Endocrinol Metab (2017) 102(5):1486-94. doi: 10.1210/jc.2016-3732

69. Sa de Camargo Etchebehere EC, Santos A, Gumz B, Vicente A, Hoff PG, Corradi G, et al. Ga-68-DOTATATE PET/CT, Tc-99m-HYNIC-Octreotide SPECT/CT, and Whole-Body Mr Imaging in Detection of Neuroendocrine Tumors: A Prospective Trial. J Nucl Med (2014) 55(10):1598-604. doi: 10.2967/jnumed.114.144543

70. Modlin I, Oberg K, Chung D, Jensen R, de Herder W, Thakker R, et al. Gastroenteropancreatic Neuroendocrine Tumours. Lancet Oncol (2008) 9 (1):61-72. doi: 10.1016/S1470-2045(07)70410-2

71. Zimmer T, Stölzel U, Bäder M, Koppenhagen K, Hamm B, Buhr H, et al. Endoscopic Ultrasonography and Somatostatin Receptor Scintigraphy in the Preoperative Localisation of Insulinomas and Gastrinomas. Gut (1996) 39 (4):562-8. doi: 10.1136/gut.39.4.562

72. Klimstra DS. Pathologic Classification of Neuroendocrine Neoplasms. Hematol Oncol Clin North Am (2016) 30(1):1-+. doi: 10.1016/j.hoc.2015.08.005

73. Ito T, Igarashi H, Jensen RT. Zollinger-Ellison Syndrome: Recent Advances and Controversies. Curr Opin Gastroenterol (2013) 29(6):650-61. doi: 10.1097/MOG.0b013e328365efb1

74. Metz DC, Jensen RT. Gastrointestinal Neuroendocrine Tumors: Pancreatic Endocrine Tumors. Gastroenterology (2008) 135(5):1469-92. doi: 10.1053/ j.gastro.2008.05.047

75. Schraml C, Schwenzer NF, Sperling O, Aschoff P, Lichy MP, Mueller M, et al. Staging of Neuroendocrine Tumours: Comparison of Ga-68 DOTATOC Multiphase PET/CT and Whole-Body MRI. Cancer Imaging (2013) 13 (1):63-72. doi: 10.1102/1470-7330.2013.0007

76. Sharma P, Naswa N, Suman SKC, Alvarado LA, Dwivedi AK, Yadav Y, et al. Comparison of the Prognostic Values of Ga-68-DOTANOC PET/CT and F18-FDG PET/CT in Patients With Well-Differentiated Neuroendocrine Tumor. Eur J Nucl Med Mol Imag (2014) 41(12):2194-202. doi: 10.1007/ s00259-014-2850-3

77. Panagiotidis E, Alshammari A, Miehopoulou S, Skoura E, Naik K, Maragkoudakis E, et al. Comparison of the Impact of Ga-68-DOTATATE and F-18-FDG PET/CT on Clinical Management in Patients With Neuroendocrine Tumors. J Nucl Med (2017) 58(1):91-6. doi: 10.2967/ jnumed.116.178095

78. Campana D, Ambrosini V, Pezzilli R, Fanti S, Labate A, Santini D, et al. Standardized Uptake Values of (68)Ga-DOTANOC PET: A Promising Prognostic Tool in Neuroendocrine Tumors. J Nucl Med: Off Publ Soc Nucl Med (2010) 51(3):353-9. doi: 10.2967/jnumed.109.066662

79. Ambrosini V, Campana D, Polverari G, Peterle C, Diodato S, Ricci C, et al. Prognostic Value of Ga-68-DOTANOC Pet/Ct SUVmax in Patients With Neuroendocrine Tumors of the Pancreas. J Nucl Med (2015) 56(12):1843-8. doi: $10.2967 /$ jnumed.115.162719

80. Ezziddin S, Opitz M, Attassi M, Biermann K, Sabet A, Guhlke S, et al. Impact of the Ki-67 Proliferation Index on Response to Peptide Receptor Radionuclide Therapy. Eur J Nucl Med Mol Imag (2011) 38(3):459-66. doi: 10.1007/s00259-010-1610-2

81. Kratochwil C, Stefanova M, Mavriopoulou E, Holland-Letz T, DimitrakopoulouStrauss A, Afshar-Oromieh A, et al. SUV of Ga-68 Dotatoc-Pet/Ct Predicts Response Probability of PRRT in Neuroendocrine Tumors. Mol Imag Biol (2015) 17(3):313-8. doi: 10.1007/s11307-014-0795-3

82. El Lakis M, Gianakou A, Nockel P, Wiseman D, Tirosh A, Quezado M, et al. Radioguided Surgery With Gallium 68 Dotatate for Patients With Neuroendocrine Tumors. JAMA Surg (2019) 154(1):40-5. doi: 10.1001/ jamasurg.2018.3475

83. Sadowski S, Millo C, Neychev V, Aufforth R, Keutgen X, Glanville J, et al. Feasibility of Radio-Guided Surgery With ${ }^{68}$ Gallium-DOTATATE in
Patients With Gastro-Entero-Pancreatic Neuroendocrine Tumors. Ann Surg Oncol (2015) 22:S676-82. doi: 10.1245/s10434-015-4857-9

84. Stueven AK, Kayser A, Wetz C, Amthauer H, Wree A, Tacke F, et al. Somatostatin Analogues in the Treatment of Neuroendocrine Tumors: Past, Present and Future. Int J Mol Sci (2019) 20(12):3049. doi: 10.3390/ ijms20123049

85. Toumpanakis C, Caplin ME. Update on the Role of Somatostatin Analogs for the Treatment of Patients With Gastroenteropancreatic Neuroendocrine Tumors. Semin Oncol (2013) 40(1):56-68. doi: 10.1053/j.seminoncol.2012.11.006

86. Kvols LK, Oberg KE, O'Dorisio TM, Mohideen P, de Herder WW, Arnold R, et al. Pasireotide (SOM230) Shows Efficacy and Tolerability in the Treatment of Patients With Advanced Neuroendocrine Tumors Refractory or Resistant to Octreotide LAR: Results From a Phase II Study. Endocr Relat Cancer (2012) 19(5):657-66. doi: 10.1530/ERC-11-0367

87. Garcia-Carbonero R, Sorbye H, Baudin E, Raymond E, Wiedenmann B, Niederle B, et al. Enets Consensus Guidelines for High-Grade Gastroenteropancreatic Neuroendocrine Tumors and Neuroendocrine Carcinomas. Neuroendocrinology (2016) 103(2):186-94. doi: 10.1159/000443172

88. Rinke A, Mueller H-H, Schade-Brittinger C, Klose K-J, Barth P, Wied M, et al. Placebo-Controlled, Double-Blind, Prospective, Randomized Study on the Effect of Octreotide LAR in the Control of Tumor Growth in Patients With Metastatic Neuroendocrine Midgut Tumors: A Report From the PROMID Study Group. J Clin Oncol (2009) 27(28):4656-63. doi: 10.1200/ JCO.2009.22.8510

89. Rinke A, Wittenberg M, Schade-Brittinger C, Aminossadati B, Ronicke E, Gress TM, et al. Placebo-Controlled, Double-Blind, Prospective, Randomized Study on the Effect of Octreotide LAR in the Control of Tumor Growth in Patients With Metastatic Neuroendocrine Midgut Tumors (Promid): Results of Long-Term Survival. Neuroendocrinology (2017) 104(1):26-32. doi: 10.1159/000443612

90. Falconi M, Eriksson B, Kaltsas G, Bartsch D, Capdevila J, Caplin M, et al. Enets Consensus Guidelines Update for the Management of Patients With Functional Pancreatic Neuroendocrine Tumors and Non-Functional Pancreatic Neuroendocrine Tumors. Neuroendocrinology (2016) 103 (2):153-71. doi: 10.1159/000443171

91. Jann H, Denecke T, Koch M, Pape UF, Wiedenmann B, Pavel M. Impact of Octreotide Long-Acting Release on Tumour Growth Control as a First-Line Treatment in Neuroendocrine Tumours of Pancreatic Origin. Neuroendocrinology (2013) 98(2):137-43. doi: 10.1159/000353785

92. Caplin ME, Pavel M, Cwikla JB, Phan AT, Raderer M, Sedlackova E, et al. Lanreotide in Metastatic Enteropancreatic Neuroendocrine Tumors. New Engl J Med (2014) 371(3):224-33. doi: 10.1056/NEJMoa1316158

93. Caplin M, Pavel M, Ćwikła J, Phan A, Raderer M, Sedláčková E, et al. AntiTumour Effects of Lanreotide for Pancreatic and Intestinal Neuroendocrine Tumours: The CLARINET Open-Label Extension Study. Endocr Relat Cancer (2016) 23(3):191-9. doi: 10.1530/ERC-15-0490

94. Phan AT, Dasari A, Liyanage N, Cox D, Lowenthal SP, Wolin EM. Tumor Response in the CLARINET Study of Lanreotide Depot vs. Placebo in Patients With Metastatic Gastroenteropancreatic Neuroendocrine Tumors (GEP-NETs). J Clin Oncol (2016) 34(4_suppl):434-. doi: 10.1200/ jco.2016.34.4_suppl.434

95. Cives M, Kunz PL, Morse B, Coppola D, Schell MJ, Campos T, et al. Phase II Clinical Trial of Pasireotide Long-Acting Repeatable in Patients With Metastatic Neuroendocrine Tumors. Endocr Relat Cancer (2015) 22(1):19. doi: 10.1530/ERC-14-0360

96. Kulke MH, Ruszniewski P, Van Cutsem E, Lombard-Bohas C, Valle JW, De Herder WW, et al. A Randomized, Open-Label, Phase 2 Study of Everolimus in Combination With Pasireotide LAR or Everolimus Alone in Advanced, Well-Differentiated, Progressive Pancreatic Neuroendocrine Tumors: COOPERATE-2 Trial. Ann Oncol (2017) 28(6):1309-15. doi: 10.1093/ annonc/mdx078

97. Vezzosi D, Bennet A, Rochaix P, Courbon F, Selves J, Pradere B, et al. Octreotide in Insulinoma Patients: Efficacy on Hypoglycemia, Relationships With Octreoscan Scintigraphy and Immunostaining With anti-sst2A and Anti-Ssts Antibodies. Eur J Endocrinol (2005) 152(5):757-67. doi: 10.1530/eje.1.01901

98. Tirosh A, Stemmer SM, Solomonov E, Elnekave E, Saeger W, Ravkin Y, et al. Pasireotide for Malignant Insulinoma. Horm-Int J Endocrinol Metab (2016) 15(2):271-6. doi: 10.14310/horm.2002.1639 
99. Maton P. Use of Octreotide Acetate for Control of Symptoms in Patients With Islet Cell Tumors. World J Surg (1993) 17(4):504-10. doi: 10.1007/BF01655110

100. Tomassetti P, Migliori M, Caletti GC, Fusaroli P, Corinaldesi R, Gullo L. Treatment of Type II Gastric Carcinoid Tumors With Somatostatin Analogues. New Engl J Med (2000) 343(8):551-4. doi: 10.1056/NEJM200008243430805

101. Tomassetti P, Campana D, Piscitelli L, Mazzotta E, Brocchi E, Pezzilli R, et al. Treatment of Zollinger-Ellison Syndrome. World J Gastroenterol (2005) 11 (35):5423-32. doi: 10.3748/wjg.v11.i35.5423

102. Prommegger R, Bale R, Ensinger C, Sauper T, Profanter C, Knoflach M, et al. Gastric Carcinoid Type I Tumour: New Diagnostic and Therapeutic Method. Eur J Gastroenterol Hepatol (2003) 15(6):705-7. doi: 10.1097/00042737200306000-00020

103. Tomassetti P, Migliori M, Corinaldesi R, Gullo L. Treatment of Gastroenteropancreatic Neuroendocrine Tumours With Octreotide LAR. Aliment Pharmacol Ther (2000) 14(5):557-60. doi: 10.1046/j.1365-2036. 2000.00738.x

104. Wermers RA, Fatourechi V, Wynne AG, Kvols LK, Lloyd RV. The Glucagonoma Syndrome - Clinical and Pathologic Features in 21 Patients. Medicine (1996) 75(2):53-63. doi: 10.1097/00005792-199603000-00002

105. Casadei R, Tomassetti P, Rossi C, la Donna M, Migliori M, Marrano D. Treatment of Metastatic Glucagonoma to the Liver: Case Report and Literature Review. Ital J Gastroenterol Hepatol (1999) 31(4):308-12.

106. Ghaferi AA, Chojnacki KA, Long WD, Cameron JL, Yeo CJ. Pancreatic VIPomas: Subject Review and One Institutional Experience. J Gastrointest Surg (2008) 12(2):382-93. doi: 10.1007/s11605-007-0177-0

107. Song S, Shi R, Li B, Liu Y. Diagnosis and Treatment of Pancreatic Vasoactive Intestinal Peptide Endocrine Tumors. Pancreas (2009) 38(7):811-4. doi: 10.1097/MPA.0b013e3181b2bc7c

108. Nakayama S, Yokote T, Kobayashi K, Hirata Y, Hiraiwa T, Komoto I, et al. Vipoma With Expression of Both VIP and VPAC1 Receptors in a Patient With WDHA Syndrome. Endocrine (2009) 35(2):143-6. doi: 10.1007/ s12020-009-9146-6

109. Angeletti S, Corleto VD, Schillaci O, Marignani M, Annibale B, Moretti A, et al. Use of the Somatostatin Analogue Octreotide to Localise and Manage SomatostatinProducing Tumours. Gut (1998) 42(6):792-4. doi: 10.1136/gut.42.6.792

110. van der Zwan WA, Bodei L, Mueller-Brand J, de Herder WW, Kvols LK, Kwekkeboom DJ. Gep-Nets UPDATE Radionuclide Therapy in Neuroendocrine Tumors. Eur J Endocrinol (2015) 172(1):R1-R8. doi: 10.1530/EJE-14-0488

111. Garkavij M, Nickel M, Sjogreen-Gleisner K, Ljungberg M, Ohlsson T, Wingardh K, et al. Lu-177- DOTA0,Tyr3 Octreotate Therapy in Patients With Disseminated Neuroendocrine Tumors: Analysis of Dosimetry With Impact on Future Therapeutic Strategy. Cancer (2010) 116(4):1084-92. doi: $10.1002 /$ cncr. 24796

112. Ramage J, Naraev BG, Halfdanarson TR. Peptide Receptor Radionuclide Therapy for Patients With Advanced Pancreatic Neuroendocrine Tumors. Semin Oncol (2018) 45(4):236-48. doi: 10.1053/j.seminoncol.2018.08.004

113. Starr JS, Sonbol MB, Hobday TJ, Sharma A, Kendi AT, Halfdanarson TR. Peptide Receptor Radionuclide Therapy for the Treatment of Pancreatic Neuroendocrine Tumors: Recent Insights. Oncol Targets Ther (2020) 13:3545-55. doi: 10.2147/OTT.S202867

114. Kwekkeboom DJ, de Herder WW, Kam BL, van Eijck CH, van Essen M, Kooij PP, et al. Treatment With the Radiolabeled Somatostatin Analog Lu177-DOTA(0), Tyr(3) Octreotate: Toxicity, Efficacy, and Survival. J Clin Oncol (2008) 26(13):2124-30. doi: 10.1200/JCO.2007.15.2553

115. Ezziddin S, Khalaf F, Vanezi M, Haslerud T, Mayer K, Al Zreiqat A, et al. Outcome of Peptide Receptor Radionuclide Therapy With Lu-177-octreotate in Advanced Grade 1/2 Pancreatic Neuroendocrine Tumours. Eur J Nucl Med Mol Imag (2014) 41(5):925-33. doi: 10.1007/s00259-013-2677-3

116. Imhof A, Brunner P, Marincek N, Briel M, Schindler C, Rasch H, et al. Response, Survival, and Long-Term Toxicity After Therapy With the Radiolabeled Somatostatin Analogue Y-90-DOTA -TOC in Metastasized Neuroendocrine Cancers. J Clin Oncol (2011) 29(17):2416-23. doi: 10.1200/ JCO.2010.33.7873

117. Kratochwil C, Giesel F, Bruchertseifer F, Mier W, Apostolidis C, Boll R, et al. ${ }^{213}$ Bi-DOTATOC Receptor-Targeted Alpha-Radionuclide Therapy Induces Remission in Neuroendocrine Tumours Refractory to Beta Radiation: A First-in-Human Experience. Eur J Nucl Med Mol Imag (2014) 41(11):210619. doi: 10.1007/s00259-014-2857-9
118. Morgenstern A, Apostolidis C, Kratochwil C, Sathekge M, Krolicki L, Bruchertseifer F. An Overview of Targeted Alpha Therapy With Actinium and Bismuth. Curr Radiopharmaceut (2018) 11(3):200-8. doi: 10.2174/ 1874471011666180502104524

119. Brons S, Jakob B, Taucher-Scholz G, Kraft G. Heavy Ion Production of Single- and Double-Strand Breaks in Plasmid DNA in Aqueous Solution. Physica Med: PM: An Int J Devoted Appl Phys Med Biol: Off J Ital Assoc Biomed Phys (AIFB) (2001) 17(Suppl. 1):217-8.

120. Kim Y, Brechbiel M. An Overview of Targeted Alpha Therapy. Tumour Biol: J Int Soc Oncodevelopmental Biol Med (2012) 33(3):573-90. doi: 10.1007/ s13277-011-0286-y

121. Nayak T, Norenberg J, Anderson T, Atcher R. A Comparison of HighVersus Low-Linear Energy Transfer Somatostatin Receptor Targeted Radionuclide Therapy In Vitro. Cancer Biother Radiopharmaceut (2005) 20(1):52-7. doi: $10.1089 /$ cbr.2005.20.52

122. Nayak T, Norenberg J, Anderson T, Prossnitz E, Stabin M, Atcher R. Somatostatin-Receptor-Targeted Alpha-Emitting 213Bi is Therapeutically More Effective Than Beta(-)-Emitting 177Lu in Human Pancreatic Adenocarcinoma Cells. Nucl Med Biol (2007) 34(2):185-93. doi: 10.1016/ j.nucmedbio.2006.11.006

123. Chan H, de Blois E, Morgenstern A, Bruchertseifer F, de Jong M, Breeman W, et al. In Vitro Comparison of 213Bi- and 177Lu-Radiation for Peptide Receptor Radionuclide Therapy. PloS One (2017) 12(7):e0181473. doi: 10.1371/journal.pone.0181473

124. Norenberg J, Krenning B, Konings I, Kusewitt D, Nayak T, Anderson T, et al. 213Bi-[DOTA0, Tyr3] octreotide Peptide Receptor Radionuclide Therapy of Pancreatic Tumors in a Preclinical Animal Model. Clin Cancer Res: An Off J Am Assoc Cancer Res (2006) 12:897-903. doi: 10.1158/1078-0432.CCR-051264

125. Miederer M, Henriksen G, Alke A, Mossbrugger I, Quintanilla-Martinez L, Senekowitsch-Schmidtke R, et al. Preclinical Evaluation of the Alpha-Particle Generator Nuclide 225Ac for Somatostatin Receptor Radiotherapy of Neuroendocrine Tumors. Clin Cancer Res: An Off J Am Assoc Cancer Res (2008) 14(11):3555-61. doi: 10.1158/1078-0432.CCR-07-4647

126. Zhang J, Singh A, Kulkarni H, Schuchardt C, Müller D, Wester H, et al. From Bench to Bedside-The Bad Berka Experience With First-in-Human Studies. Semin Nucl Med (2019) 49(5):422-37. doi: 10.1053/j.semnuclmed.2019.06.002

127. Ballal S, Yadav M, Bal C, Sahoo R, Tripathi M. Broadening Horizons With Ac-DOTATATE Targeted Alpha Therapy for Gastroenteropancreatic Neuroendocrine Tumour Patients Stable or Refractory to Lu-DOTATATE PRRT: First Clinical Experience on the Efficacy and Safety. Eur J Nucl Med Mol Imag (2020) 47(4):934-46. doi: 10.1007/s00259-019-04567-2

128. Dumont RA, Seiler D, Marincek N, Brunner P, Radojewski P, Rochlitz C, et al. Survival After Somatostatin Based Radiopeptide Therapy With Y-90DOTATOC vs. Y-90-DOTATOC Plus Lu-177-DOTATOC in Metastasized Gastrinoma. Am J Nucl Med Mol Imaging (2015) 5(1):46-55.

129. Grozinsky-Glasberg S, Barak D, Fraenkel M, Walter MA, Mueller-Brand J, Eckstein J, et al. Peptide Receptor Radioligand Therapy is an Effective Treatment for the Long-Term Stabilization of Malignant Gastrinomas. Cancer (2011) 117(7):1377-85. doi: 10.1002/cncr.25646

130. van Schaik E, van Vliet EI, Feelders RA, Krenning EP, Khan S, Kamp K, et al. Improved Control of Severe Hypoglycemia in Patients With Malignant Insulinomas by Peptide Receptor Radionuclide Therapy. J Clin Endocrinol Metab (2011) 96(11):3381-9. doi: 10.1210/jc.2011-1563

131. Magalhães D, Sampaio IL, Ferreira G, Bogalho P, Martins-Branco D, Santos R, et al. Peptide Receptor Radionuclide Therapy With (177)Lu-DOTATATE as a Promising Treatment of Malignant Insulinoma: A Series of Case Reports and Literature Review. J Endocrinol Invest (2019) 42(3):249-60. doi: 10.1007/s40618-018-0911-3

132. Zandee WT, Brabander T, Blazevic A, Kam BLR, Teunissen JJM, Feelders RA, et al. Symptomatic and Radiological Response to Lu-177-DOTATATE for the Treatment of Functioning Pancreatic Neuroendocrine Tumors. J Clin Endocrinol Metab (2019) 104(4):1336-44. doi: 10.1210/jc.2018-01991

133. Wild D, Fani M, Behe M, Brink I, Rivier JEF, Reubi JC, et al. First Clinical Evidence That Imaging With Somatostatin Receptor Antagonists is Feasible. J Nucl Med (2011) 52(9):1412-7. doi: 10.2967/jnumed.111.088922

134. Wild D, Fani M, Fischer R, Del Pozzo L, Kaul F, Krebs S, et al. Comparison of Somatostatin Receptor Agonist and Antagonist for Peptide Receptor 
Radionuclide Therapy: A Pilot Study. J Nucl Med (2014) 55(8):1248-52. doi: 10.2967/jnumed.114.138834

135. Nicolas G, Schreiter N, Kaul F, Uiters J, Bouterfa H, Kaufmann J, et al. Sensitivity Comparison of Ga-OPS202 and Ga-DOTATOC PET/CT in Patients With Gastroenteropancreatic Neuroendocrine Tumors: A Prospective Phase Ii Imaging Study. J Nucl Med: Off Publ Soc Nucl Med (2018) 59(6):915-21. doi: 10.2967/jnumed.117.199760

136. Nicolas G, Beykan S, Bouterfa H, Kaufmann J, Bauman A, Lassmann M, et al. Safety, Biodistribution, and Radiation Dosimetry of Ga-OPS202 in Patients With Gastroenteropancreatic Neuroendocrine Tumors: A Prospective Phase I Imaging Study. J Nucl Med: Off Publ Soc Nucl Med (2018) 59(6):909-14. doi: $10.2967 /$ jnumed.117.199737

137. Dalm S, Nonnekens J, Doeswijk G, de Blois E, van Gent D, Konijnenberg M, et al. Comparison of the Therapeutic Response to Treatment With a $177 \mathrm{Lu}-$
Labeled Somatostatin Receptor Agonist and Antagonist in Preclinical Models. J Nucl Med: Off Publ Soc Nucl Med (2016) 57(2):260-5. doi: 10.2967/jnumed.115.167007

Conflict of Interest: The authors declare that the research was conducted in the absence of any commercial or financial relationships that could be construed as a potential conflict of interest.

Copyright (๑) $2021 \mathrm{Hu}, \mathrm{Ye}$, Wang, Qin, $\mathrm{Xu}, \mathrm{Yu}$ and Ji. This is an open-access article distributed under the terms of the Creative Commons Attribution License (CC BY). The use, distribution or reproduction in other forums is permitted, provided the original author(s) and the copyright owner(s) are credited and that the original publication in this journal is cited, in accordance with accepted academic practice. No use, distribution or reproduction is permitted which does not comply with these terms. 